\title{
Allelic variation at the interleukin $1 \beta$ gene is associated with decreased bone mass in patients with inflammatory bowel diseases
}

\author{
A Nemetz, M Tóth, M A García-González, T Zágoni, J Fehér, A S Peña, Z Tulassay
}

\begin{abstract}
Background-Interleukin $1 \beta$ (IL-1ß) and its natural antagonist have been implicated in the pathogenesis of inflammatory bowel disease (IBD). Both cytokines influence bone formation. IL-1 $\beta$ stimulates osteoclast activity while interleukin 1 receptor antagonist (IL-1ra) enhances bone formation.
\end{abstract}

Aims-To determine whether the decreased bone mass in IBD is related to gene polymorphisms coding for IL-1 $\beta$ and IL-1 ra, and thus identify patients with an increased risk.

Methods-Bone mineral densitometry was performed at the femoral neck, lumbar spine, and the distal third of the radius in 75 IBD patients ( $34 \mathrm{men} / 41$ women; 40.3 (1.6) years) and in 58 healthy controls (HC; $28 \mathrm{men} / 30$ women; 32.4 (1.2) years). Values were correlated with the TaqI and AvaI gene polymorphisms in the $I L 1 B$ and the variable number of tandem repeats gene polymorphism in the IL1RN gene.

Results-In IBD patients, but not in HC, carriers of allele 2 at the AvaI gene polymorphism (IL1B-511*2) had significantly lower $Z$ scores at the lumbar spine $(-0.82(0.13) v-0.29(0.21) \mathrm{p}=0.03)$ and the femoral neck $(-0.59(0.14) v 0.15(0.19)$; $\mathbf{p}=0.003)$ than non-carriers. These patients also had a higher risk for osteopenia or osteoporosis at the femoral neck (odds ratio 3.63 (95\% confidence interval $0.95-$ 13.93)). No association was found between bone mass and the other gene polymorphisms analysed in IBD patients or in HC. Conclusions-Our results suggest that genetic variability may be a major determinant of bone loss in IBD. Carriers of $I L 1 B-511^{\star} 2$, who are hypersecretors of IL-1 $\beta$, have a higher risk of presenting with low bone mass in IBD. Screening for this allele may contribute to determination of the risk of bone loss at the time of disease onset.

(Gut 2001;49:644-649)

Keywords: inflammatory bowel diseases; ulcerative colitis; Crohn's disease; osteoporosis; bone density; genetic polymorphisms; interleukin 1

Correspondence to: Professor A S Peña, Department of Gastroenterology, PO 7057, $1007 \mathrm{MB}$ Amsterdam, the Netherlands.

as.pena@vumc.nl

ANemetz.humgen@med.vu.nl

Accepted for publication 19 December 2000 reduced bone mass in patients with IBD may include the causes of idiopathic osteoporosis, as well as specific factors related to the inflammatory process.

Cytokines influence bone remodelling by regulating differentiation as well as the activity of osteoclasts and osteoblasts. A key proinflammatory cytokine interleukin $1 \beta$ (IL- $1 \beta$ ) stimulates osteoclast development and activity, ${ }^{2}$ and was found to decrease bone collagen and noncollagen protein synthesis. ${ }^{3}$ The naturally occurring antagonist of $\mathrm{IL}-1 \beta$, the interleukin 1 receptor antagonist (IL-1ra), stimulates bone formation and decreases the number of osteoclasts on the endocortical surfaces. ${ }^{4}$ Moreover, greater spinal bone loss was observed among premenopausal women with higher stimulated production of IL-1 $\beta .^{5}$ Spontaneous secretion of IL-1 by cultured peripheral blood mononuclear cells was significantly higher in osteoporotic patients compared with healthy subjects. ${ }^{6}$

As in high turnover osteoporosis, enhanced circulating levels of IL-1 $\beta$ have been reported in patients with IBD. ${ }^{7}$ The altered production and mucosal ratio of IL- $1 \beta$ and IL- 1 ra is strongly suggested to be a pathogenic factor in IBD..$^{8-10}$ Increased production of IL-1 $\beta$ was implicated as a possible reason for increased bone loss in IBD. ${ }^{11}$

Family, twin, and epidemiological studies indicate that genetic factors play an important role in determining bone mass. ${ }^{12-14}$ Assessment of bone turnover markers suggests a genetic influence in the regulation of bone metabolism. ${ }^{15}$ Although there is evidence that the genotype influences both peak bone mass and the rate of bone loss, no overall susceptibility genes for osteoporosis have yet been identified. ${ }^{16-21}$ The inconsistencies of candidate gene studies are due to the multifactorial regulation of bone mineral density: a polygenic predisposition is modified by environmental and lifestyle factors.

As members of the IL-1 family play an important role in the regulation of bone formation, genes involved in the control of their activity provide other candidate loci for susceptibility to increased bone loss. Indeed, allelic variations at the IL-1 receptor antagonist gene

Abbreviations used in this paper: IBD, inflammatory bowel disease; CD, Crohn's disease; UC, ulcerative colitis; HC, healthy controls; IL-1 $\beta$, interleukin $1 \beta$; IL-1 ra, interleukin 1 receptor antagonist; IL1B, interleukin $1 \beta$ gene; IL1RN, interleukin 1 receptor antagonist gene; IL $1 B-511^{\star} 2$, allele 2 in the $I L 1 B$ gene at position -511 ; OR, odds ratio; RFLP, restriction fragment length polymorphism; VNTR, variable number of tandem repeats; $\mathrm{BMD}$, bone mineral density. 
Table 1 Clinical characteristics of inflammatory bowel disease (IBD) patients according to their carriership of allele IL1B-511*2

\begin{tabular}{llll}
\hline & $\begin{array}{l}\text { Non-carriers of allele } \\
\text { IL1B-511*2 } \\
(n=24)\end{array}$ & $\begin{array}{l}\text { Carriers of allele } \\
\text { IL1B-511 } \\
(n=51)\end{array}$ & p Value \\
\hline Age (y) & $40.6(2.5)$ & $40.1(2.0)$ & 0.98 \\
Sex (F/M) & $11 / 13$ & $29 / 22$ & 0.37 \\
Disease type (UC/CD) & $12 / 12$ & $27 / 24$ & 0.81 \\
Disease duration (y) & $11.0(1.6)$ & $7.5(1.6)$ & 0.26 \\
Body mass index (kg/m $\left.{ }^{2}\right)$ & $24.04(0.87)$ & $22.57(0.47)$ & 0.08 \\
Ever received systemic steroids (yes/no) & $17 / 7$ & $37 / 14$ & 0.88 \\
Lifetime steroid dose $>3$ g (n) & 9 & 20 & 0.89 \\
Hemicolectomy (n) & 2 & 6 & 1.00 \\
Ileal resection (n) & 1 & 3 & 1.00 \\
Disease location & 10 & 20 & \\
$\quad$ CD involving the small bowel (n) & 2 & 4 & 1.00 \\
CD not involving the small bowel (n) & 0 & 3 & 0.22 \\
UC: proctitis (n) & 6 & 17 & \\
UC: left sided disease (n) & 6 & 7 & \\
UC: total colitis (n) & & & \\
\hline
\end{tabular}

Values are mean (SE).

UC, ulcerative colitis; CD, Crohn's disease.

(IL1RN) were found to be associated with early postmenopausal bone loss at the spine. ${ }^{22}$ Further evidence on the genetic control of bone loss comes from studies of Cox and colleagues. ${ }^{23}$ These authors found a linkage between the severe forms of rheumatoid arthritis characterised by bone erosions and the IL1 gene cluster, while this linkage was not present in the non-erosive form of the disease. ${ }^{23}$ As to the actual influence of allelic variations on cytokine levels, production of both IL-1 $\beta$ and IL-1ra protein are related to the TaqI and AvaI genetic polymorphisms in the IL-1 $\beta$ (IL1B) and the variable number of tandem repeats (VNTR) polymorphism in the IL1RN gene. ${ }^{24-26}$ An allelic combination of these polymorphisms in the $I L 1 B$ gene was found to be associated with the disease course in CD. Among CD patients with non-fistulising disease, homozygotes for allele 1 at the TaqI site were more frequently carriers of allele 2 at the AvaI polymorphic site while this was not found in healthy controls or in patients with fistulising $\mathrm{CD} .{ }^{27}$

Based on previous observations, this study aimed to answer the question whether genetic polymorphisms in the IL1B and IL1RN genes influence bone mass in patients with IBD compared with healthy controls.

\section{Materials and methods}

PATIENTS

Seventy five patients with IBD, 39 patients with UC (17 men/22 women; aged 43 (2.6) years) and 36 with CD (17 men/19 women; aged 35 (1.8) years), were included in the study. A group of 58 healthy individuals (HC) (28 men/30 women; aged 32 (1.2) years) served as control subjects. The sample size was made up from those unrelated individuals of Hungarian origin of the invited 100 IBD patients and 120 HC. Diagnosis and extent of IBD were determined by conventional clinical, endoscopic/radiological, and histopathological criteria. ${ }^{28}$ One CD patient had a childhood disease onset; hemicolectomy had been performed on seven CD and one UC patient while ileal resection had been carried out in four cases. Categories for classification of CD patients were set according to the Vienna classification $^{29}$ : seven had terminal ileal, six colonic, and 19 ileocolic disease, while four patients had additional upper gastrointestinal disease location. $\mathrm{Z}$ scores for patients with a location including the small bowel were not different from the rest of the IBD group. No patient received hormone replacement therapy or any bone active drugs other than corticosteroids. Sixteen IBD patients were taking over the counter multivitamin/mineral supplements in regular daily doses (table 1) The ethics committees of the participant universities approved the study. Informed consent was obtained from all patients.

\section{DNA ISOLATION, POLYMORPHISM TYPING}

Genomic DNA was extracted from EDTA anticoagulated peripheral blood according to the standard proteinase- $\mathrm{K}$ digestion and phenol-chloroform extraction method. Two biallelic restriction fragment length polymorphisms (RFLP) at positions -511 and +3953 of the ILIB gene and a penta-allelic VNTR polymorphism in the ILIRN gene were determined according to previously described methods. ${ }^{27}$ 30-32 Summarised conditions are given in table 2 .

BONE MINERAL DENSITOMETRY

Bone mineral densitometry was performed by dual $x$ ray absorptiometry at the left femoral neck, lumbar spine $\left(\mathrm{L}_{2}-\mathrm{L}_{4}\right)$, and the distal third of the non-dominant radius using a Hologic QDR 4500C instrument (Hologic Inc., Waltham, Massachusetts, USA). The longitudinal precision of measurements on a Hologic spine phantom has a coefficient of variation of $0.35 \%$. Data were obtained for absolute areal bone density $\left(\mathrm{g} / \mathrm{cm}^{2}\right)$ and were also expressed as the number of SDs below or above the age and sex standardised average ( $Z$ scores). According to the recommendations of the WHO, $\mathrm{T}$ score values were used (the number

Table 2 Reaction conditions used for detection of interleukin 1 (IL1) gene family polymorphisms

\begin{tabular}{|c|c|c|c|c|}
\hline Position & Primers (5' to 3') & $\begin{array}{l}\text { Annealing temp } \\
\left({ }^{\circ} \mathrm{C}\right)\end{array}$ & $\begin{array}{l}\text { Type of } \\
\text { polymorphism }\end{array}$ & Alleles \\
\hline$I L 1 B-511$ & $\begin{array}{l}\text { Sense: TGGCATTTGATCTGGTTCATC } \\
\text { Antisense: GTTTAGGAATCTTCCCACTT }\end{array}$ & 55 & AvaI RFLP & $\begin{array}{l}1=\text { Digested fragment }(190 \mathrm{bp} \text { and } 115 \mathrm{bp}) \\
2=\text { Intact fragment }(305 \mathrm{bp})\end{array}$ \\
\hline IL1B+3954 & $\begin{array}{l}\text { Sense: GTTGTCATCAGACTTTGACC } \\
\text { Antisense: TTCAGTTCATATGGACCAGA }\end{array}$ & 55 & TaqI RFLP & $\begin{array}{l}1=\text { Digested fragment }(135 \mathrm{bp} \text { and } 114 \mathrm{bp}) \\
2=\text { Intact fragment }(249 \mathrm{bp})\end{array}$ \\
\hline$I L 1 R N 2$ nd intron & $\begin{array}{l}\text { Sense: CTCAGCAACACTCCTAT } \\
\text { Antisense: TCCTGGTCTGCAGGTAA }\end{array}$ & 60 & VNTR & $\begin{array}{l}1=4 \text { repeats of the } 86 \text { bp region }(410 \mathrm{bp}) \\
2=2 \text { repeats }(240 \mathrm{bp}) \\
3=5 \text { repeats }(500 \mathrm{bp}) \\
4=3 \text { repeats }(325 \mathrm{bp}) \\
5=6 \text { repeats }(595 \mathrm{bp})\end{array}$ \\
\hline
\end{tabular}

RFLP, restriction fragment length polymorphism; VNTR, variable number of tandem repeats. 
Table 3 Bone mass (mean (SE)) in carriers and non-carriers of allele IL1B-511 2 among patients with inflammatory bowel disease

\begin{tabular}{llll}
\hline & $\begin{array}{l}\text { Non-carriers of allele } \\
\text { IL1B-511*2 } \\
(n=24)\end{array}$ & $\begin{array}{l}\text { Carriers of allele } \\
\text { IL1B-511*2 } \\
(n=51)\end{array}$ & p Value \\
\hline $\begin{array}{l}\text { Bone mineral density }\left(\mathrm{g} / \mathrm{cm}^{2}\right) \\
\quad \text { Lumbar spine (L2-L4) }\end{array}$ & $1.03(0.03)$ & $0.96(0.02)$ & 0.03 \\
$\quad \begin{array}{l}\text { Femoral neck } \\
\text { Radius distal 1/3 }\end{array}$ & $0.85(0.03)$ & $0.76(0.02)$ & 0.007 \\
$\mathrm{Z}$ scores & $0.72(0.03)$ & $0.70(0.02)$ & $\mathrm{NS}$ \\
$\quad$ Lumbar spine (L2-L4) & $-0.29(0.21)$ & $-0.82(0.13)$ & 0.03 \\
$\quad$ Femoral neck & $+0.15(0.19)$ & $-0.59(0.14)$ & 0.003 \\
$\quad$ Radius distal 1/3 & $-0.45(0.20)$ & $-0.80(0.17)$ & $\mathrm{NS}$ \\
\hline
\end{tabular}

of SDs above or below the sex adjusted reference values of young healthy adults) to determine the prevalence of osteopenia and osteoporosis in the patient subgroups.

STATISTICAL ANALYSIS

Statistical analyses were performed using the Statistica 5.1 Software package (Statsoft. Inc., Tulsa, USA). Individuals were divided into carriers and non-carriers of allele 2 at each polymorphic locus. The clinical characteristics of the patient subgroups were compared by $\chi^{2}$ test (for small sample sizes Fisher's exact test) or when appropriate by Student's $t$ test. Multivariate analysis of variance (MANOVA) was used to assess differences in bone mass between carriers and non-carriers of allele 2, separately for each polymorphic site. If a significant difference was found, odds ratios (OR) with their $95 \%$ confidence intervals (CI) were calculated to estimate the relative risk of pathologically low bone mass for carriers compared with non-carriers of the specific gene polymorphism. Bonferroni correction was used to reduce the risk of $\alpha$, the error of the first kind, when the analysis was performed separately for each gender. Results are reported as mean (SE).

\section{Results}

There were no significant differences in $\mathrm{Z}$ scores between patients with $\mathrm{CD}$ and UC (lumbar spine $-0.64(0.18) v-0.64(0.17)$; femoral neck $-0.46(0.16) v-0.38(0.16)$; radius $-0.85(0.09) v-0.62(0.19))$ and therefore we analysed IBD patients as one group. $I L 1 B$ and ILIRN genotype frequencies in $\mathrm{HC}$ and IBD patients were similar to those reported previously. ${ }^{27}{ }^{33}$

In IBD patients, the MANOVA test showed significant differences between bone mineral density (BMD) values of carriers and noncarriers of allele 2 at the AvaI polymorphic site

Table $4 Z$ scores (mean (SEM)) of carriers and non-carriers of allele 2 at the $I L 1 B+3954$ and the IL1RN variable number of tandem repeat (VNTR) polymorphic sites in inflammatory bowel disease patients

\begin{tabular}{llll}
\hline & Non-carriers of allele 2 & Carriers of allele 2 & p Value \\
\hline $\begin{array}{llll}\text { IL1B TaqI site } \\
\text { No patients }\end{array}$ & 51 & 24 & \\
Lumbar spine (L2-L4) & $-0.74(0.15)$ & $-0.46(0.17)$ & NS \\
$\quad$ Femoral neck & $-0.38(0.15)$ & $-0.29(0.19)$ & NS \\
Radius distal & $-0.77(0.16)$ & $-0.52(0.20)$ & NS \\
IL1RN VNTR site & & 38 & \\
$\quad$ No patients & 37 & $-0.67(0.15)$ & NS \\
Lumbar spine (L2-L4) & $-0.64(0.17)$ & $-0.43(0.18)$ & NS \\
Femoral neck & $-0.26(0.15)$ & $-0.81(0.19)$ & NS \\
Radius distal & $-0.55(0.17)$ & & \\
\hline
\end{tabular}

$\left(I L 1 B-511^{\star} 2\right)$. Carriers of allele $I L 1 B-511^{\star} 2$ had significantly lower BMD values at the lumbar spine $(\mathrm{p}=0.03)$ and at the femoral neck $(p=0.007)$ while at the radius the difference did not reach statistical significance (overall MANOVA $p=0.048$ ) (table 3 ). These findings were also present when sex and age standardised $\mathrm{Z}$ scores were compared (lumbar spine $\mathrm{p}=0.03$; femoral neck $\mathrm{p}=0.003$; overall MANOVA $\mathrm{p}=0.03$ ) (table 3 ). The relative risk of low bone mass (osteopenia or osteoporosis) at the femoral neck was also higher for carriers of allele $I L 1 B-511^{\star} 2$. Among the 23 patients with low bone mass detected at this site, only three were non-carriers of the IL $1 B-511 * 2$ allele (OR 3.63; 95\% CI 0.95-13.93). However, this phenomenon could not be observed at the lumbar spine (OR 1.47; 95\% CI $0.46-4.68$ ) or at the radius (OR $1.5 ; 95 \%$ CI $0.36-6.26)$.

No association was found at any of these locations between the number of IL $1 B-511$ *2 alleles present in an individual and the severity of bone loss ( $\mathrm{Z}$ scores of heterozygotes $v$ homozygotes for allele IL1B-511*2: lumbar spine $-0.85(0.15) v-0.76(0.28)$; femoral neck $-0.61(0.16) v-0.54(0.26)$; radius -0.86 $(0.19) v-0.61(0.37))$.

There were no significant differences between the groups of carriers and non-carriers of allele $I L 1 B-511^{\star} 2$ in terms of age, age at disease onset, body mass index, ratio of patients with CD and UC, or occurrence of corticosteroid therapy in their anamnesis (table 1). Similarly, we found no significant differences in male/female ratios between carriers and noncarriers of the $I L 1 B-511^{\star} 2$ allele. However, when analysing male and female IBD patients separately, in men there was a significant association between lower $\mathrm{Z}$ scores and the presence of allele $I L 1 B-511^{\star} 2$ both at the lumbar spine $(\mathrm{p}=0.01)$ and at the femoral neck $(p=0.038)$ while in women there was no association at the lumbar spine but only at the femoral neck. Moreover, after correction for multiple comparisons, the difference found at the femoral neck in women was no longer significant.

There was no association in IBD patients between $\mathrm{Z}$ scores and the presence of allele 2 at the VNTR gene polymorphism in the IL1RN gene $\left(I L 1 R N^{\star} 2\right)$ or the presence of allele 2 at the TaqI gene polymorphism in the IL1B (table 4). Similarly, in HC, no association was found between bone mineral density and carriership of allele 2 at any of the investigated polymorphic sites (carriers $v$ non-carriers of allele IL1B-511*2: lumbar spine $1.00(0.02) v 1.03$ (0.02); femoral neck 0.84 (0.03) v 0.89 (0.03); radius $0.71(0.01) v 0.71(0.02))$. No significant association was found between the -511 and +3954 gene polymorphisms in our HC while the frequency of the $I L 1 B-511^{\star} 2$ allele was higher in the IBD than in the control population $(0.44 \% v 0.31 \%)$.

\section{Discussion}

The pathogenesis of reduced bone mineral density in IBD is not fully understood. Patients 
with corticosteroid treatment, small bowel disease or intestinal resection, or a longstanding or extensive disease have been suggested to be at a higher risk of bone loss. However, there is no consensus in different studies as to which factor is significant in the evolution of decreased bone mass. ${ }^{1134-36}$ Moreover, a high prevalence of low bone mineral density was found in patients with newly diagnosed CD and among IBD patients with a low risk of metabolic bone disease. ${ }^{11}$ These results raise the possibility that other factors, present already before the onset of the disease, contribute to the low bone mass and enhanced bone loss in IBD patients.

In this study we have found that the presence of the $I L 1 B-511^{\star} 2$ allele was associated with significantly lower $\mathrm{Z}$ scores and a higher risk of osteopenia and osteoporosis in IBD patients. This allele has previously been related to increased in vitro production of IL- $1 \beta$ by mononuclear cells. ${ }^{25}$ Elevated levels of IL-1 $\beta$ and/or an imbalance between IL-1 $\beta$ and IL-1 ra production could result in increased bone loss. IL-1 $\beta$ was described as enhancing bone resorption by increasing the number and activity of osteoclasts while having no effect on bone formation. Animal studies have also suggested that IL-1ra treatment decreased the activity and number of osteoclasts on endocortical surfaces. ${ }^{4}$ Previous studies in IBD have shown increased bone resorption rates while levels of bone formation markers were similar to those of healthy individuals. ${ }^{1137}$ Thus the lower bone mass of IBD patients can be partly explained by elevated IL- $1 \beta$ levels and increased IL-1 $\beta$ / IL-1 ra ratio observed in these diseases.

Similar to our findings, the study of Keen and colleagues ${ }^{22}$ suggested the importance of IL1 genes in determining bone mass. In their population of early postmenopausal women, an association was found between the presence of the $I L 1 R N^{\star} 2$ allele and reduced bone loss at the spine. This allele has previously been related to increased production of IL- $1 \mathrm{ra}^{24}$ Thus in patients carrying the $I L 1 R N^{\star} 2$ allele, IL-1 $\beta$ could induce a smaller biological response when competing for binding to IL-1 receptors. However, in the study of Keen et al, an association was only seen between the ILIRN polymorphisms and the rate of bone loss, not with actual $\mathrm{Z}$ scores, whereas in the present study the $I L 1 B-511$ polymorphism was found to influence bone mass in IBD. These differences may be due to the different ages of the study groups, to the presence of IBD, or to the different end point of the studies.

As there is evidence that $I L 1 B$ genotype influences the course of IBD, ${ }^{27}{ }^{32}$ these results suggest that the inflammatory process alters regulation of bone resorption, as previously described. Our earlier studies found a higher frequency of the $I L 1 B-511 \star 2$ allele among UC patients whose leading symptom was diarrhoea than among those presenting with spontaneous rectal bleeding. ${ }^{27}$ Therefore, we propose that a specific disease course related to or manifested as alterations in the nature of intestinal absorption - such as an accelerated passage or greatly increased intestinal permeability causing dysregulated absorption-may be associated with a higher extent of bone loss. For instance, a recently published study has found that intestinal permeability is also a useful predictor of relapse in patients with CD and faecal calprotectin in both CD and UC. ${ }^{38}$

Genetic variations in the IL1B gene have been linked to several other chronic multifactorial diseases such as adult periodontal disease, ${ }^{39}{ }^{40}$ insulin dependent diabetes mellitus, ${ }^{41}$ and schizophrenia. ${ }^{42}$ Thus we could hypothesise that the $I L 1 B$ gene, by controlling the production of IL-1 $\beta$, influences the severity and course of different diseases. Additional genetic, environmental, and lifestyle factors or infections would determine if any of these diseases develops. Although we could not fully confirm the lack of association between the $I L 1 B-511$ polymorphism and BMD in the general population because of the smaller number of individuals in the HC group in this study, our results suggest that the underlying bowel disease resulting in long term upregulated IL- $1 \beta$ production may be necessary to induce bone loss. A recently published study has also shown an example of interaction of the IL-1 gene cluster and additional host factors towards progression to disease. A higher frequency of the $I L 1 B-511 \star 2$ allele among Helicobacter pylori infected relatives of gastric cancer patients with low acid secretion was found but not among those not infected with $H$ pylori. ${ }^{43}$ Moreover, the study also found almost total linkage disequilibrium between the IL1B polymorphisms at positions -511 and -31 , this latter being a TATA box polymorphism markedly affecting DNA-protein interactions in vitro.

Our results suggest that sex may be an important modifying factor in IBD. Male sex was reported to be an independent risk factor for osteoporosis in earlier studies. ${ }^{35}$ It is currently accepted that oestrogen plays a key role in the regulation of bone turnover in both sexes. ${ }^{446}$ Recent studies have demonstrated that oestrogens reduce expression of signalling type IL-1 receptor (IL-1RI) in osteoclasts while it increases expression of decoy type IL-1 receptor (IL-1RII), together decreasing IL-1 bioresponsiveness of these cells. ${ }^{47}$ This regulatory effect of oestrogen was similar in cells from both male and female donors. In contrast, steady state IL-1RII/IL-1RI ratios in osteoclast-like cells of men were found to be lower than those of early postmenopausal women, suggesting that similar IL- $1 \beta$ levels may have a stronger bone resorptive effect in men than in women.

In this study the association between the genotype of the AvaI gene polymorphism and bone mass in IBD patients was strongest at the femoral neck. This is in agreement with other studies reporting a greater prevalence of reduced hip BMD in IBD compared with the frequency of vertebral or forearm osteopenia. ${ }^{11} 3488$ This would further confirm that the pathogenesis of bone loss in IBD is different from the clearly steroid induced bone disease, which affects vertebrae to a greater extent. 
Although several general and IBD related osteoporosis risk factors are suspected to contribute to the increased bone loss in IBD, results on the extent of their roles are controversial and are not applicable to predicting osteopenia in the long term at the time of diagnosis of the disease. We have shown that carriers of the $I L 1 B-511^{\star} 2$ allele have a higher risk of presenting with low bone mass in IBD. These results may extend our knowledge regarding the pathogenesis of low bone mass in IBD patients. Furthermore, screening for the AvaI gene polymorphism in the IL1B gene could contribute towards determining the risk of bone loss in IBD patients at the time of disease onset. Early identification of patients at high risk of osteoporosis could help to set up more effective "tailor made" therapy. Our results, together with the recent study in Gastroenterology, ${ }^{49}$ suggest that genetic variability may be a major determinant of bone loss in IBD.

We would like to acknowledge the financial support of AstraZeneca, the Netherlands, to MA García-González. A Nemetz was supported by the "Vrije Universiteit Vrouwen Fonds". We thank E Dinya and P Vargha for help in performing the statistical analysis. Preliminary work was presented in the "Genetics of IBD" thematic session at the 7th UEGW meeting in Rome, and the abstract has been published in Gut 1999;45(suppl V): A15.

1 Compston JE, Judd D, Crawley EO, et al. Osteoporosis in patients with inflammatory bowel disease. Gut patients with

2 Pfeilschifter J, Chenu C, Bird A, et al. Interleukin-1 and tumour necrosis factor stimulate the formation of human osteoclast-like cells in vitro. F Bone Miner Res 1989;4:11318.

3 Smith DD, Gowen M, Mundy GR. Effects of interferongamma and other cytokines on collagen synthesis in fetal rat bone cultures. Endocrinology 1987;120:2494-9.

4 Kimble R, Matayoshi A, Vannice J, et al. Simultaneous block of interleukin-1 and tumour necrosis factor is required to completely prevent bone loss in the early postovariectomy period. Endocrinology 1995;136:3054-61.

5 Salamone LM, Whiteside T, Friberg D, et al. Cytokine production and bone mineral density at the lumbar spine and femoral neck in premenopausal women. Calcif Tissue Int 1998;63:466-70.

6 Pacifici R, Rifas L, Teitelbaum S, et al. Spontaneous release of interleukin 1 from human blood monocytes reflects bone formation in idiopathic osteoporosis. Proc Natl Acad Sci USA 1987;84:4616-20

7 Nakamura M, Saito H, Kasanuki J, et al. Cytokine production in patients with inflammatory bowel disease. Gut 1992;33:933-7.

8 Casini-Raggi V, Kam L, Chong YJ, et al. Mucosal imbalance of IL-1 and IL-1 receptor antagonist in inflammatory bowel disease. A novel mechanism of chronic intestinal inflammation. F Immunol 1995;154:2434-40.

9 Hyams JS, Fitzgerald JE, Wyzga N, et al. Relationship of interleukin-1 receptor antagonist to mucosal inflammation in inflammatory bowel disease. 7 Pediatr Gastroenterol Nutr 1995;21:419-25.

10 Reimund JM, Wittersheim C, Dumont S, et al. Mucosal inflammatory cytokine production by intestinal biopsies in Immunol 1996;16:144-50.

11 Bjarnason I, Macpherson A, Mackintosh C, et al. Reduced bone density in patients with inflammatory bowel disease. bone density in patient

12 Evans RA, Marel GM, Lancaster EK, et al. Bone mass is low in relatives of osteoporotic patients. Ann Intern Med 1988; 109:870-3.

13 Young D, Hopper JL, Nowson CA, et al. Determinants of bone mass in 10 - to 26 -year-old females: a twin study. $\mathcal{F}$ Bone Miner Res 1995;10:558-67.

14 Cummings SR, Cauley JA, Palermo L, et al. Racial differences in hip axis lengths might explain racial differences in rates of hip fracture. Study of Osteoporotic Fractures Research Group. Osteoporos Int 1994;4:226-9.

15 Kelly PJ, Hopper JL, Macaskill GT, et al. Genetic factors in bone turnover. F Clin Endocrinol Metab 1991;72:808-13.

16 Morrison NA, Qi JC, Tokita A, et al. Prediction of bone density

17 Kobayashi S, Inoue S, Hosoi T, et al. Association of bone mineral density with polymorphism of the estrogen receptor gene. F Bone Miner Res 1996;11:306-11.

18 Langdahl BL, Knudsen JY, Jensen HK, et al. A sequence variation: $713-8 \mathrm{delC}$ in the transforming growth factorbeta 1 gene has higher prevalence in osteoporotic women than in normal women and is associated with very low bone mass in osteoporotic women and increased bone turnover 997;20: 289-9

19 Grant SF, Reid DM, Blake G, et al. Reduced bone density and osteoporosis associated with a polymorphic Sp1 binding site in the collagen type I alpha 1 gene. Nat Genet 1996; 14:203-5.

20 Cooper GS, Umbach DM. Are vitamin D receptor polymorphisms associated with bone mineral density? A meta-analysis. I Bone Miner Res 1996;11:1841-9.

21 Han KO, Moon IG, Kang YS, et al. Nonassociation of estrogen receptor genotypes with bone mineral density and estrogen responsiveness to hormone replacement therapy in Korean postmenopausal women. $\mathcal{F}$ Clin Endocrinol Metab 1997;82:991-5.

22 Keen RW, Woodford-Richens KL, Lanchbury JS, et al. Allelic variation at the interleukin-1 receptor antagonist gene is associated with early postmenopausal bone loss at the spine. Bone 1998;23:367-71.

23 Cox A, Camp NJ, Cannings C, et al. Combined sib-TDT and TDT provide evidence for linkage of the interleukin-1 gene cluster to erosive rheumatoid arthritis. Hum Mol Genet 1999;8:1707-13.

24 Danis VA, Millington M, Hyland VJ, et al. Cytokine production by normal human monocytes: inter-subject variation and relationship to an IL-1 receptor antagonist (IL-1Ra) gene polymorphism. Clin Exp Immunol 1995;99: 303-10

25 Santtila S, Savinainen K, Hurme M. Presence of the IL-1RA allele 2 (IL1RN ${ }^{\star} 2$ ) is associated with enhanced IL-1beta production in vitro. Scand $\mathcal{F}$ Immunol 1998;47: 195-8.

26 Hurme M, Santtila S. IL-1 receptor antagonist (IL-1Ra) plasma levels are co-ordinately regulated by both IL-1 Ra and IL-1beta genes. Eur F Immunol 1998;28:2598-602.

27 Nemetz A, Nosti-Escanilla M, Molnár T, et al. IL-1 beta gene polymorphisms influence the course and severity of inflammatory bowel disease. Immunogenetics 1999;49:52731.

28 Lennard-Jones JE. Classification of inflammatory bowel disease. Scand $\mathcal{F}$ Gastroenterol Suppl 1989;170:2-6.

29 Gasche C, Schölmerich J, Brynskov J, et al. A simple classification of Crohn's disease; Report of the Working Party for the World Congresses of Gastroenterology, Vienna 1998. Inflamm Bowel Dis 2000;6:8-15.

30 di Giovine FS, Takhsh E, Blakemore AI, et al. Single base polymorphism at -511 in the human interleukin-1 beta gene (IL1 beta). Hum Mol Genet 1992;1:450.

31 Pociot F, Molvig J, Wogensen L, et al. A TaqI polymorphism in the human interleukin-1 $\beta$ (IL-1 $\beta$ ) gene correlates with IL-1 $\beta$ secretion in vitro. Eur F Clin Invest 1992;22:396-402.

32 Bioque G, Crusius JB, Koutroubakis I, et al. Allelic polymorphism in IL-1 beta and IL-1 receptor antagonist (IL-1Ra) genes in inflammatory bowel disease. Clin Exp (IL-1Ra) genes in inflammat

33 Nemetz A, Köpe A, Molnár T, et al. Significant differences in the interleukin-1 beta and interleukin-1 receptor antagonist gene polymorphisms in a Hungarian population with inflammatory bowel disease. Scand $\mathscr{f}$ Gastroenterol 1999;34: $175-9$.

34 Silvennoinen JA, Karttunen TJ, Niemela SE, et al. A controlled study of bone mineral density in patients with inflammatory bowel disease. Gut 1995;37:71-6.

35 Jahnsen J, Falch JA, Aadland E, et al. Bone mineral density is reduced in patients with Crohn's disease but not in patients with ulcerative colitis: a population based study. Gut 1997;40:313-19.

36 Pollak RD, Karmeli F, Eliakim R, et al. Femoral neck osteopenia in patients with inflammatory bowel disease. Am $\mathcal{F}$ Gastroenterol 1998;93:1483-90.

37 Silvennoinen J, Risteli L, Karttunen T, et al. Increased degradation of type I collagen in patients with inflammatory bowel disease. Gut 1996;38:223-8.

38 Tibble JA, Sigthorsson G, Bridger S, et al. Surrogate markers of intestinal inflammation are predictive of relapse in patients with inflammatory bowel disease. Gastroenterology 2000;119:15-22.

39 Kornman KS, Crane A, Wang HY, et al. The interleukin-1 genotype as a severity factor in adult periodontal disease. $f$ Clin Periodontol 1997;24:72-7.

40 Gore EA, Sanders JJ, Pandey JP, et al. Interleukin1beta+3953 allele 2: association with disease status in adult periodontitis. F Clin Periodontol 1998;25:781-5.

41 Loughrey BV, Maxwell AP, Fogarty DG, et al. An interleukin $1 \mathrm{~B}$ allele, which correlates with a high secretor phenotype, is associated with diabetic nephropathy. Cytophenotype, is associate

42 Katila H, Hanninen K, Hurme M. Polymorphisms of the interleukin-1 gene complex in schizophrenia. Mol Psychiatry 1999;4:179-81.

43 El-Omar EM, Carrington M, Chow W-H, et al. Interleukin-1 polymorphisms associated with increased risk of gastric cancer. Nature 2000;404:398-402.

44 Smith EP, Boyd J, Frank GR, et al. Estrogen resistance caused by a mutation in the estrogen-receptor gene in a man. N Engl f Med 1994;331:1056-61.

45 Lorenzo JA, Naprta A, Rao Y, et al. Mice lacking the type I interleukin-1 receptor do not lose bone mass after ovariectomy. Endocrinology 1998;139:3022-5.

46 Riggs BL, Khosla S, Melton LJ, 3rd. A unitary model for involutional osteoporosis: estrogen deficiency causes both type I and type II osteoporosis in postmenopausal women 
and contributes to bone loss in aging men. 7 Bone Miner Res 1998:13:763-73.

47 Sunyer T, Lewis J, Collin-Osdoby P, et al. Estrogen's boneprotective effects may involve differential IL-1 receptor regulation in human osteoclast-like cells. F Clin Invest 1999;103:1409-18.
48 Ghosh S, Cowen S, Hannan WJ, et al. Low bone mineral density in Crohn's disease, but not in ulcerative colitis at density in Crohn's disease, but not in ulcer

49 Schulte CM, Dignass AU, Goebell H, et al. Genetic factors determine extent of bone loss in inflammatory bowel disease. Gastroenterology 2000;119:909-20.

\section{7th European Forum on Quality Improvement in Health Care}

\section{1-23 March 2002 \\ Edinburgh, Scotland}

We are delighted to announce this forthcoming conference in Edinburgh. Delegate enquiries are welcome.

The themes of the Forum are:

- Leadership, culture change, and change management

- Achieving radical improvement by redesigning care

- Health policy for lasting improvement in health care systems

- Patient safety

- Measurement for improvement, learning, and accountability

- Partnership with patients

- Professional quality: the foundation for improvement

- Continuous improvement in education and training

- People and improvement.

Presented to you by the BMJ Publishing Group (London, UK) and Institute for Healthcare Improvement (Boston, USA). For more information contact: quality@bma.org.uk or look at the website www.quality.bmjpg.com. Tel: +44 (0)20 7383 6409; fax: +44 (0)20 73736869 . 